\title{
Optimization of insulation on subsea oil and gas equipment
}

\author{
Ramechecandane Somassoundirame ${ }^{1}\left[\right.$ [D Eswari Nithiyananthan ${ }^{2}$
}

Received: 7 November 2020 / Accepted: 9 December 2020 / Published online: 12 January 2021

(c) The Author(s) 2021

\begin{abstract}
Optimization of insulation on subsea oil and gas equipment can lead to significant cost and weight reduction. A judicious combination of commercially available Finite Element Analysis (FEA) software with evolutionary optimization algorithms can efficiently serve this purpose. In the present study, the optimization of insulation on a gate valve has been presented with due emphasis on the methodology adapted. A parameterized model of the gate valve with several dimensions of interest has been chosen for the numerical experiment. Of the various Design of Experiment (DOE) techniques, the Optimal Space Filling (OSF) method has been considered for generating the samples owing to its robustness and the associated computational cost. The insulation in subsea systems is usually supposed to satisfy two contradicting constraints, it must be ensured that the temperature of the production fluid remains above the Hydrate Formation Temperature (HFT) and at the same time the production fluid temperature cannot be too high, as to create structural damage of the seals in High Pressure High Temperature (HPHT) applications. The sample cases are run simultaneously in a cluster and a response surface is created using genetic aggregation using the various samples those are generated by OSF. The resulting response surface is finally subjected to optimization using the calculus based/gradient based methods. In the present investigation, the optimization is performed using the NonLinear Programming with Quadratic Lagrangian (NLPQL) and Adaptive Single Objective (ASO) Methods. The results obtained show that almost two thirds of the insulation can be effectively removed without compromising on the thermal efficiency of the system. Similar savings have been witnessed in several other cases/subsea geometries that the authors are aware of. The presented case is truly representative of a wide class of subsea applications and the proposed methodology can be suitably adjusted to customer specific requirements to provide suitable results.
\end{abstract}

Keywords Optimization · Insulation · Subsea oil and gas equipment · Optimal space filling · Adaptive single objective method $\cdot$ Non-linear programming with quadratic lagrangian

\section{Introduction}

The world is still reeling under the pressure of the pandemic and the organizations are increasingly focused on cost-cutting measures and retaining market share in a dramatically shrinking economy. To stay relevant, the companies are crunching numbers more than ever before and exploring possibilities of cost reduction at every aspect of the business processes. The current outbreak of a pandemic coupled with an already lack luster demand for oil and gas has evolved as

Ramechecandane Somassoundirame

rsomass1@jh.edu

Eswari Nithiyananthan

nithiyanante1@gator.uhd.edu

Johns Hopkins University, Baltimore, MD, USA

2 University of Houston Downtown, Houston, TX, USA an existential threat for most oil and gas companies. Companies are increasingly focused on cost reduction without compromising on the quality of the deliverable. The art of optimization can be effectively utilized to achieve superior products by considerably avoiding wastage and rework. Optimization has remained as a challenging area of research for several decades and multiple sectors of manufacturing have immensely benefited from these efforts. There exists great potential to apply these techniques of optimization to augment production and to improvise on the cost cutting efforts in oil and gas companies. From the exploration of oil and gas fields to the supply of refined fuel to the customer, the oil and gas companies deal with large sets of data at every stage of the business cycle. The science of optimization can be successfully applied to every-stage of the business and product life-cycle. In the present numerical investigation, the prime focus is restricted to the optimization of insulation 
on subsea oil and gas equipment. The proposed methodology can be readily extended to every product design. By adopting this technique at the design stage of the product the engineers can avoid significant rework and redesign. Quite often the design of the subsea components involves too many parameters and is far beyond the comprehension of a novice. Even seasoned Engineers may find it extremely difficult to account for every design parameter. The modern day computers can come in handy when handling too many parameters.

Since the advent of modern computers, the art of computing has undergone tremendous improvements. It has become increasingly possible to crunch large data sets and simulate processes those were once deemed to be impossible. The science of optimization has become more sophisticated and moved from the hands of mathematicians to engineers. Most present-day consumer appliances are optimized to suit customer requirements, but even the optimization of a simple product involves an extensive list of objectives and numerous constraints. At times, there are contradicting objectives or constraints that can make optimization quite challenging. There are multiple ways of solving an optimization problem and there exists numerous documentations on the same. Fortunately, the commercial tools available for performing optimization studies have improved tremendously over time. In the present study, ANSYS ${ }^{\circledR}$ DesignXplorer is used for the optimization of insulation on subsea production systems and their components. Numerous mathematical techniques/ models have evolved to optimize components and systems in various branches of engineering. Optimization methods can be broadly classified into three:

1. Search methods

2. Calculus-based/gradient-based methods

3. Evolutionary algorithms

The search methods are more time consuming and their accuracy depends on the nature of the objective functions and varies with the number of iterations. These methods are generally used for uni-modal problems where in the objective function has a single maxima or minima. For example, in the bi-section method, the solution domain is split into halves after every iteration and the algorithm searches for an optimal solution. If there are multiple modes, then the algorithm will fail with a local optimum which may not be the global optima for the objective function. The calculus-based methods are based on the Newton's method and are more suitable for differentiable objective functions. The calculusbased method are the most accurate as they calculate the optimum solution based on the gradients and mathematically these are the best methods available. There are several commercial codes using this form of optimization algorithm. The commercial code ANSYS ${ }^{\circledR}$ DesignXplorer has a set of gradient based algorithms which are highly efficient in solving single objective functions with multiple constraints (both equality and inequality constraints). The evolutionary algorithms are like search algorithms but are based on the mechanics of natural selection. The most popular being genetic algorithm, simulated annealing, and so on. The most widely accepted evolutionary algorithm is the Genetic Algorithm, which is broadly referred to as GA. The traditional form of GA works with bits and binaries.

In the present study, the optimization of insulation on a subsea gate valve has been carried out using NonLinear Programming with Quadratic Lagrangian (NLPQL) and Adaptive Single Objective (ASO) algorithms. Although there exist several studies on optimization of subsea systems, the availability of literature on the optimization of insulation in subsea applications is quite meager. A judicious combination of the various numerical techniques can lead to a significant cost reduction, as demonstrated in the present work. A parameterized model of the insulation is used for the surface response based optimization methods under consideration. An efficient blend of Design of Experiments (DOE) and optimization methods applied to subsea systems has not been adequately explored in existing literature.

\section{Literature survey}

Even though there exists abundance of literature on optimization, the number of papers that have bestowed attention exclusively on subsea applications are quite limited. The optimization studies those are performed on the subsea systems are mostly concentrated on the field layout and the configuration of the systems/sub-systems. There exist very few papers on component level optimization that the authors are aware of. An overview of the literature reviewed is presented in the ensuing paragraphs.

One of the early studies in the $70 \mathrm{~s}$ on optimization of oil and gas fields was performed by Durrer and Slater (1977). The paper presents a comprehensive survey of literature dealing with the optimization of petroleum and natural gas production: Drilling, reservoir simulation, production planning and operations, and enhanced recovery processes. Areas of possible future work were identified, such as optimal design and cost benefit studies of enhanced recovery projects.

Pribytkov et al. (2014) performed Optimization studies on Integrated Template Structures for Arctic Subsea-Production Systems. They investigated four different scenarios with differing number of integrated template structures (ITS) and well slots. Various parameters affecting the cost of subsea infrastructure were analyzed and studied from different perspectives such as the geometrical well-pattern systems, distance between drilling slots, drilling and construction costs. 
Finally, an optimal ITS for the Arctic/Sub-Arctic region was created.

Philip et al. (2020) performed studies to analyze and compare the influence of the diameter selection on the optimal gathering system position. The optimal position of the manifolds was calculated using genetic algorithm. The results show that the flowline and trunk line diameter are critical for maximizing efficiency, and that the manifold's optimal position is greatly affected by certain changes in flowline diameter.

Bieker et al. (2006) in their paper on real-time production optimization presented the information flow used for optimization of an offshore oil production plant. The elements in their description include data acquisition, data storage, processing facility model updating, well model updating, reservoir model updating, production planning, reservoir planning, and strategic planning. Methods for well allocation, gas lift and gas/water injection optimization and updating of the models were reviewed in relationship with the information flow described. Challenges of real-time optimization were discussed.

Ramdial et al. (2009) performed a model based optimization of a gas production system. The Asset system has been tested in several real production situations to Identify potential oil production increases. Cheng et al. (2020) proposed an optimization model for the insulation material volume of a rigid subsea flowline system. The best insulation thickness of each subsea flowline was determined under given flow parameters and temperature requirements. Pavel et al. (2014) performed studies on automated insulation optimization of subsea equipment. Thermal FEA or CFD was used to simulate the cooldown of the equipment to design and verify the equipment insulation design. According to Pavel et al. such automated design process clearly brings direct cost/ weight savings, but also opens the door to standardization and smarter engineering.

Jahanshahi et al. (2016) in their paper on optimization presented a unifying fluid model using B-splines. The applicability of their method was demonstrated in two examples, and the results obtained were compared with realistic Olga simulator output. Zhang et al. (2017) used four improved particle swarm optimization algorithms for design of subsea oil pipelines. The proposed model was applied for analyzing the thermal-hydraulic and structural forces, and subsequently solving the main pipeline parameters. Monte Carlo method was also introduced into the algorithms to determine the uncertainty parameters. Yang et al. (2018) proposed an optimization method that can decrease the cost of insulation and at the same time can meet the thermal requirements of the system. Yang et al. used linear regression to predict the minimum temperature with an acceptable level of accuracy. They also concluded that the insulation material that requires minimum insulation volume can be comparatively more expensive than the other alternatives. Bhattacharyya and Cheliyan (2019) proposed a method of optimizing a fault tree using a non-dominated sorting genetic algorithm (NSGA-II). The problem considered for optimization was one of leakage in a subsea production system. They explored both single and two objective approaches to optimization and their corresponding numerical convergence features.

There exist several papers on real-time optimization of subsea productions but the individual components that comprise the system/sub-system has not been paid adequate attention. The works of Bieker et al. (2006, 2007), Saputelli et al. (2003a, b), Mochizuki et al. (2004), Elgoeter et al. (2010) are all focused on real-time optimization and there exist very few papers on the optimization of individual components (Zhang et al. (2017), Yang et al. (2018), Cheng et al. (2020) and Pavel et al. (2014)). The present study bestows attention on the optimization of an individual component, namely the insulation using both calculus/gradient based optimization techniques and evolutionary algorithms. A comparison of results obtained using the two optimization methods is presented in the results and discussion section.

\section{Analysis workflow}

The sequence of operations performed to achieve the final optimized model are as follows:

1. Parameterized model for analysis - the geometry file must be parameterized using any CAD modeler and each parameter must be named properly for future reference and traceability.

2. The FEA analysis is set up with the corresponding initial and boundary conditions using the commercial code. In this study, ANSYS Steady State Thermal and Transient Thermal are used along with ANSYS Design Xplorer.

3. The samples are generated using an available Design of Experiment (DOE) scheme. Based on the computational time the best possible DOE scheme must be chosen. The Central Composite Design (CCD) is the most desirable, as it runs several cases within the design space. In the present study, due to the limitation on the computational time/cost, the optimal space filling technique (OSF) has been used. For the sake of brevity, the detailed explanation of these DOE schemes is avoided.

4. The analyses run simultaneously in the cluster, the computational time increases significantly based on the number of parameters and samples chosen. As a rule of thumb there must be at least 10 samples for each parameter considered.

5. A response surface is created using the meta-models available in Design Xplorer. For the present study

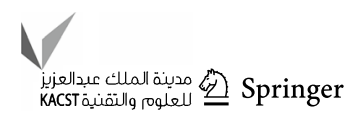




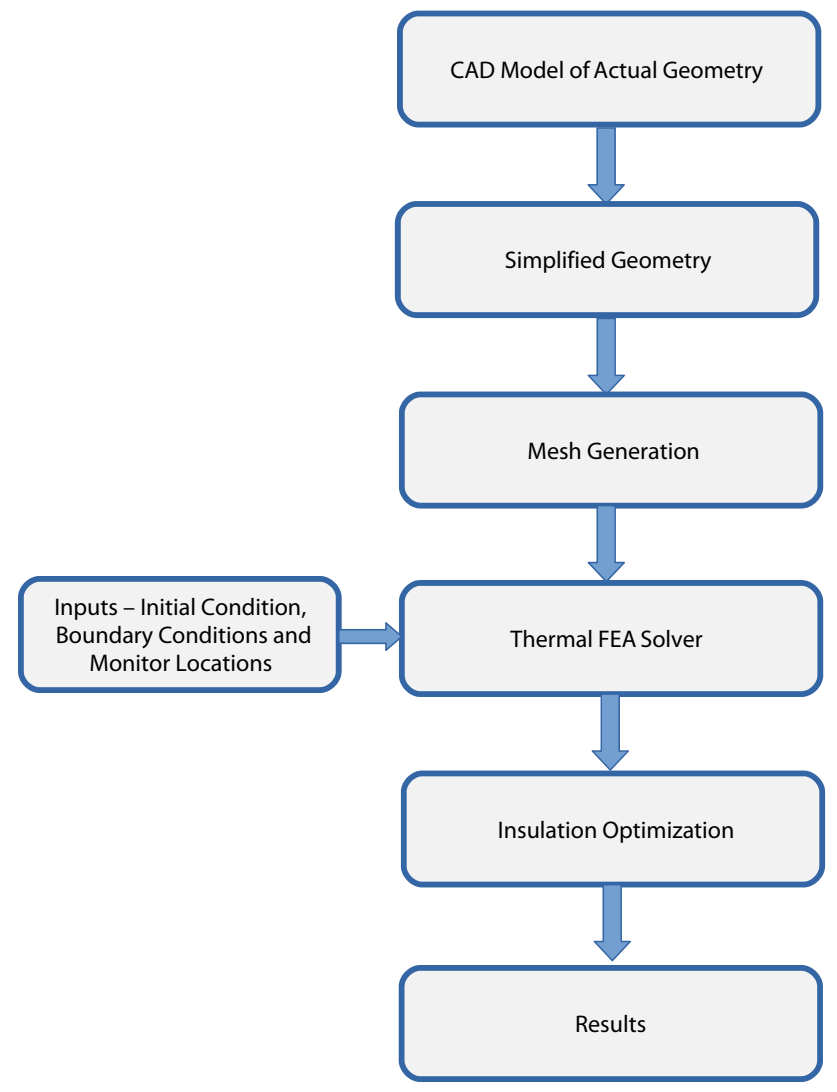

Fig. 1 Workflow for the finite element analysis (FEA)

genetic aggregation has been used for creating the response surface.

6. Finally, the optimization routine run on the response surface to determine the best possible solution for the problem under consideration.

The thermal FEA/cooldown analysis workflow and the optimization workflow are presented in Figs. 1 and 2.

The present study revolves around the optimization of insulation on subsea equipment. ANSYS ${ }^{\circledR}$ DesignXplorer was used for performing the numerical investigations. ANSYS $®$ DesignXplorer' user guide explicitly mentions that a good design point is often the result of a trade-off between various objectives and the exploration of a given design that cannot be performed by using optimization algorithms that lead to a single design point. It also emphasizes that it is important to gather enough information about the current design to be able to answer the so called what-if questions. DesignXplorer or any tool for optimization describes the relationship between design variables and the performance of the product by using Design of Experiments (DOE), combined with response surfaces. Once the relationship between the objective function and the design variables
Parameterized Model Created in CAD Modeler

(AutoCAD, NX, Catia, Autodesk Inventor etc.)

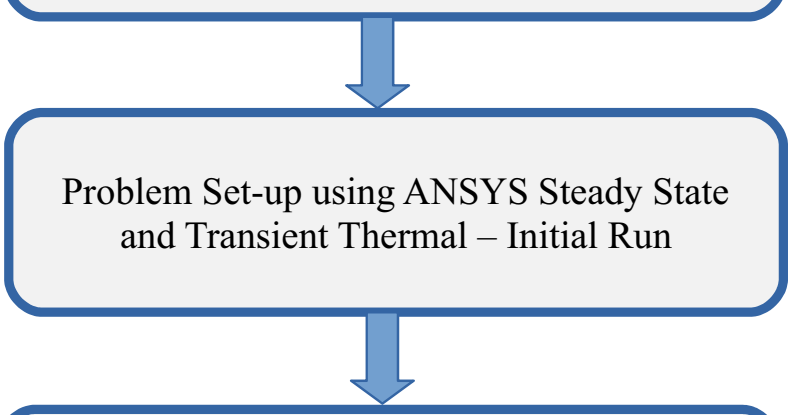

Samples Generated using Design of Experiment (DOE) Schemes - OSF for this Study

Analysis Run in Parallel - at least 10 runs for each Parameter

Response Surface is Fit using Generated Results

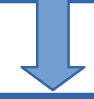

Optimization Program is Run on the Response Surface to Retrieve the Desired Maxima/Minima - Final Results

Fig. 2 Workflow for the insulation optimization routine

is known then it is extremely easy to identify all changes required to meet the requirements of a product.

\section{Design of experiments/sampling schemes}

Central composite design (CCD) generates a traditional DOE sampling set, whereas Optimal Space Filling (OSF) provides the fewest number of sampling points. For a detailed study 
of these DOE schemes, the readers are encouraged to refer to the User's Guide of ANSYS ${ }^{\circledR}$ DesignXplorer.

\section{Response surfaces}

After sampling, DesignXplorer provides several different meta-models to represent the simulations responses. The meta-models available in ANSYS ${ }^{\circledR}$ DesignXplorer can accurately represent highly nonlinear responses. Genetic aggregation has been used for generating the response surface for the present investigation.

\section{Optimization algorithms}

The problem considered for the present investigation is a single objective multi-constraint problem. The types of optimization algorithms available for single objective optimization are quite vast. In the present study, the nonlinear programming with quadratic Lagrangian (NLPQL) and the adaptive single-objective optimization (ASO) are considered to ensure the consistency of the solutions obtained. These techniques are quite different, as NLPQL is a calculus/gradient based method and the adaptive single-objective optimization (ASO) is an evolutionary algorithm. It has been noticed that the methods can yield slightly different results as each has its own inherent advantages and disadvantages. The DOE methods used also could affect the results to a certain extent.

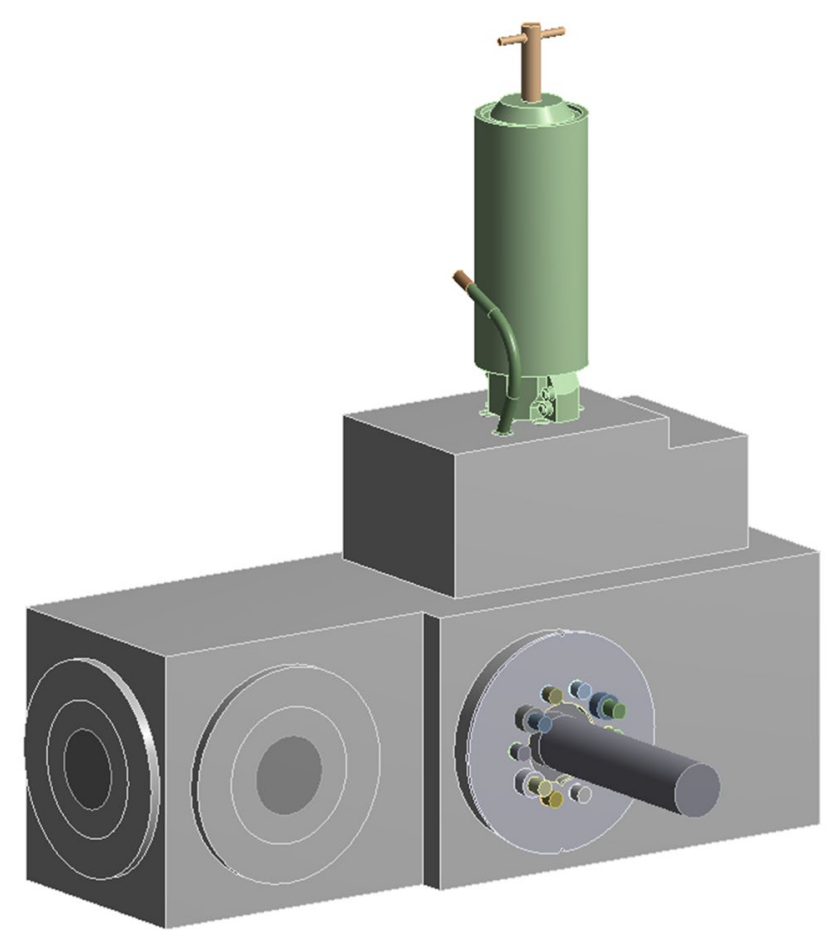

Fig. 3 Geometry of the gate valve
It is even possible to integrate external optimization programs/software with DesignXplorer. The NonLinear Programming with Quadratic Lagrangian NLPQL, Mixed Integer Sequential Programming (MISQP) and Adaptive Single-Objective Optimization (ASO) are schemes exclusively meant for a single objective multi-variate optimization problem. The Multi-Objective Genetic Algorithm (MOGA) and Adaptive Multi-Objective Optimization (AMO) are based on the genetic algorithm and can be effectively used for multi-objective optimization problems.

In the present study as the objective is just to optimize the insulation volume/weight, calculus based approaches such as NLPQL and MISQP are sufficient. However, MISQP can handle more variables and constants and usually is the best option. If there are multiple objectives, then one must resort to genetic algorithm based schemes such as MOGA or AMO.

\section{Problem set-up}

To demonstrate the methodology adapted to optimize the insulation on various subsea components, the insulation on a gate valve has been considered for the optimization study. The geometry considered for the present investigation is a gate valve as shown in Fig. 3. The optimization around the gate valve is shown in gray color in Fig. 3. The thermophysical properties of the materials considered for the present analysis are listed in Table 1.

The vast majority of the parts in the valve body comprises of metals that have thermo-physical properties similar to those of 8630, and in order to be conservative all the metal bodies are assumed to be 8630 in the present study. The insulation has a lower thermal diffusivity and hence can retain the heat within the system for a longer period of time.

Table 1 Thermo-physical properties of materials

\begin{tabular}{llll}
\hline Material & Density $\left(\mathrm{kg} / \mathrm{m}^{3}\right)$ & $\begin{array}{l}\text { Specific heat } \\
\text { capacity }(\mathrm{J} / \mathrm{kg} \mathrm{K})\end{array}$ & $\begin{array}{l}\text { Thermal } \\
\text { conductivity } \\
(\mathrm{W} / \mathrm{m} \mathrm{K})\end{array}$ \\
\hline 8630 & 7833 & 477 & 46.6 \\
Insulation & 950 & 1450 & 0.17 \\
\hline
\end{tabular}

Table 2 Thermo-physical properties of production fluid and seawater

\begin{tabular}{llll}
\hline Fluid & Density $\left(\mathrm{kg} / \mathrm{m}^{3}\right)$ & $\begin{array}{l}\text { Specific heat } \\
\text { capacity }(\mathrm{J} / \\
\mathrm{kg} \mathrm{K})\end{array}$ & $\begin{array}{l}\text { Thermal } \\
\text { conductivity } \\
(\mathrm{W} / \mathrm{m} \mathrm{K})\end{array}$ \\
\hline $\begin{array}{l}\text { Production fluid } \\
\text { Seawater }\end{array}$ & 0.716 & 2260.9 & 0.035 \\
& 1035 & 4168 & 0.59 \\
\hline
\end{tabular}


The thermo-physical properties of the production fluid and seawater considered for the present investigation have the been presented in Table 2 .

The mating components upstream and downstream have been ignored in the present analysis. As the parameters considered for the present investigation is more than 10 , it is better to restrict such analysis to one product at a time. To perform an insulation optimization of a Christmas Tree (XT) or a manifold it is better to split the domain into segments and then integrate them to ensure the results obtained are satisfactory.

The insulation on the gate valve in the original/initial design occupies a volume of $0.14 \mathrm{~m}^{3}$. The prime objective here is to minimize the insulation volume and hence has been considered as the objective function. The constraint that has been set for the optimization analysis is the cooldown/Hydrate Formation Temperature (HFT). The minimum temperature after a duration of $8 \mathrm{~h}$ is expected to be greater than $21^{\circ} \mathrm{C}\left(70{ }^{\circ} \mathrm{F}\right)$. The mesh generated for the present study consists of $\sim 2.5$ million elements. The mesh generated for the original geometry is shown in Fig. 4.

A mesh independence/sensitivity study has been performed to ensure that the solution is truly grid independent. The number of elements used for the present analyses is 2.5 million. The results obtained have been compared with the results from a finer mesh ( $\sim 6$ milllion elements). For the sake of brevity, the results obtained from the mesh sensitivity study have not been presented in this paper. The variation

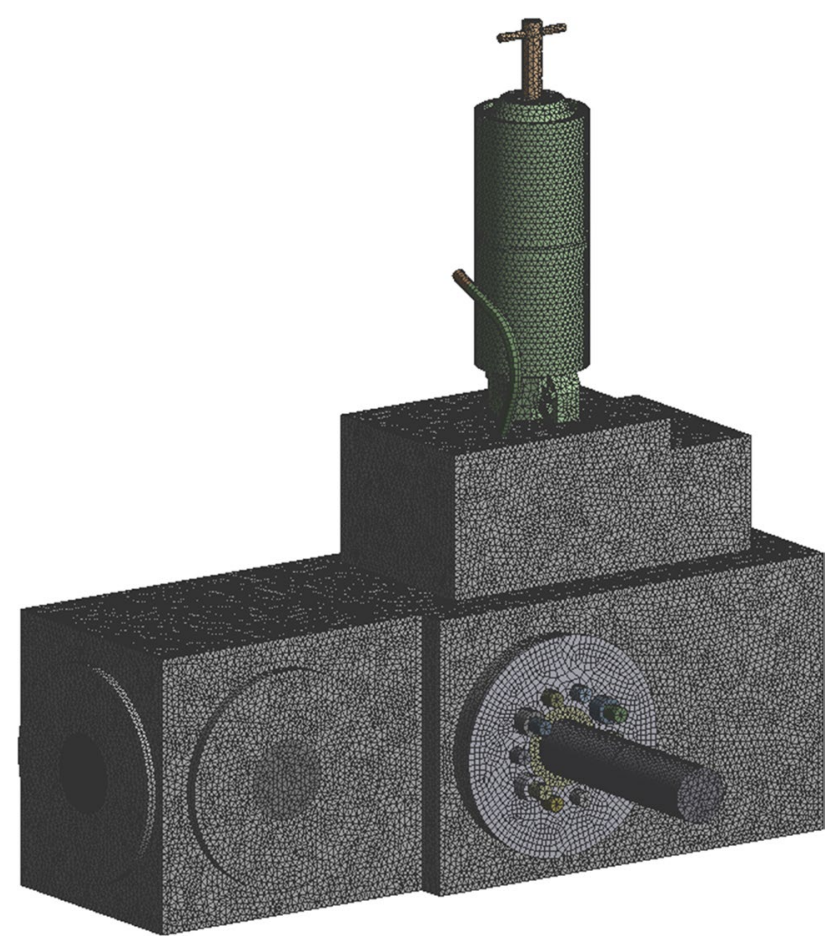

Fig. 4 Mesh generated for the gate valve

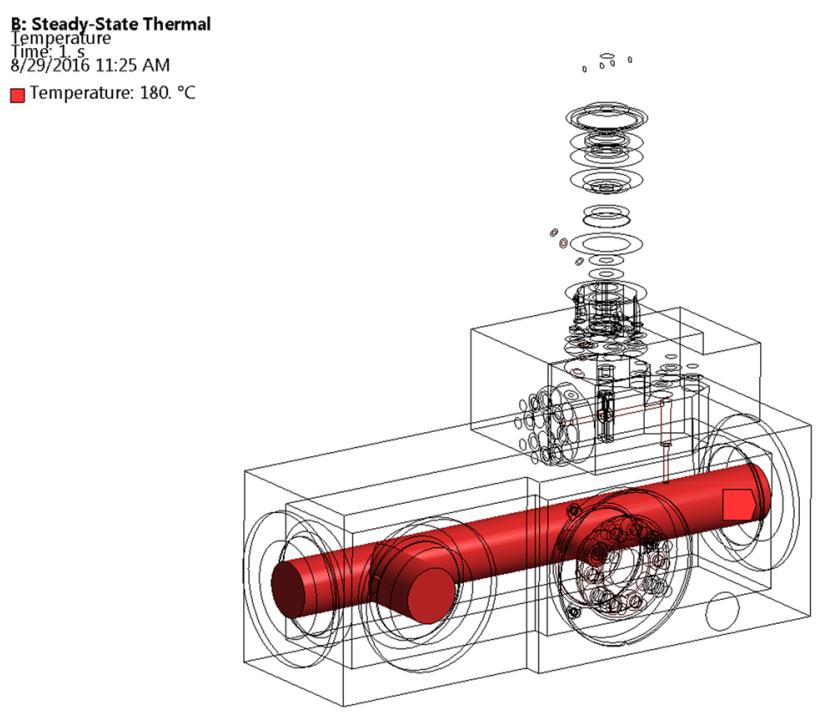

Fig. 5 Initial condition - bore temperature of $180^{\circ} \mathrm{C}\left(356^{\circ} \mathrm{F}\right)$

of the results is less than $0.1 \%$ and hence the results from the present study can be totally relied upon.

The bore temperature/production fluid temperature of $180^{\circ} \mathrm{C}\left(356^{\circ} \mathrm{F}\right)$ is assumed for the present analysis. The Dirichlet's (Isothermal) condition is applied for the production fluid in the steady state analysis. The isothermal bore is shown in Fig. 5. This serves as the initial condition for the steady state thermal FEA performed before the transient cooldown analysis.

The convective heat transfer coefficients are specified on the outer surfaces of the insulation and the metal bodies as shown in Figs. 6 and 7. The heat transfer coefficients are calculated using the standard empirical correlations from

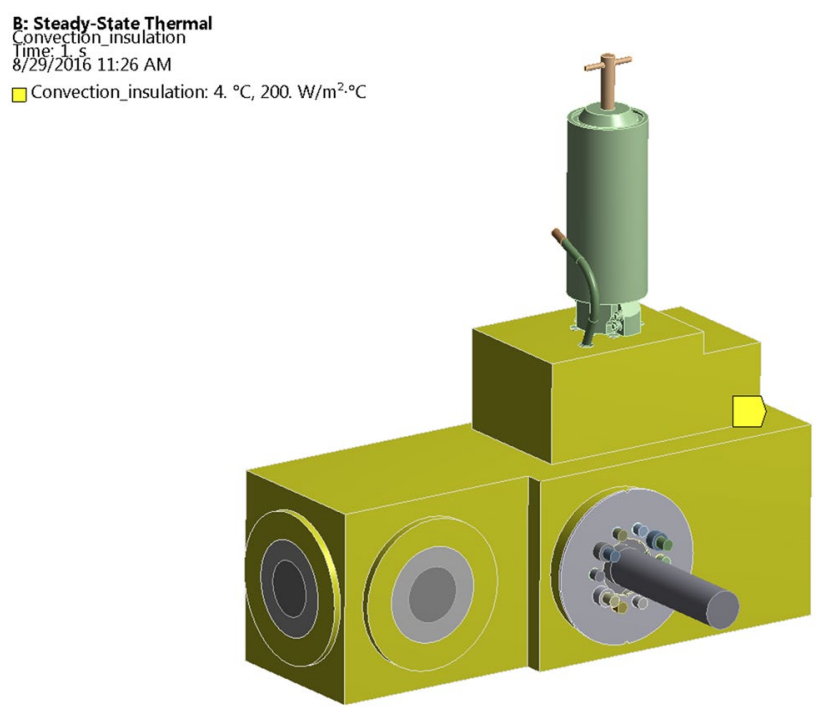

Fig. 6 Convective boundary condition on the insulation 


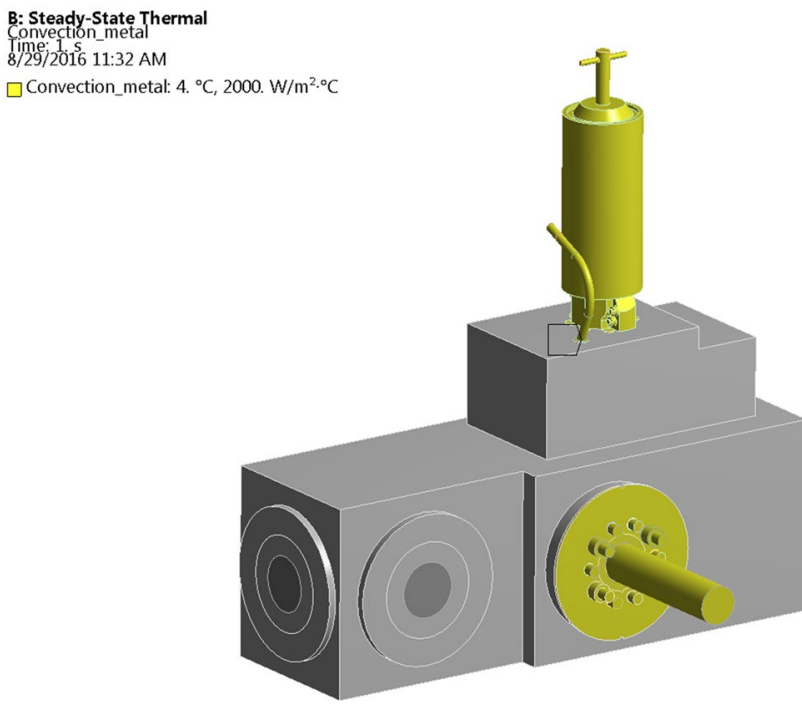

Fig. 7 Convective boundary condition on the metal body surfaces

Incropera and Dewitt (2006) and Cengel and Ghajar (2010). The heat transfer coefficients are iteratively determined using a program created in Fortran that performs an energy balance and seeks the heat transfer coefficient on the outer surface of the bodies iteratively. The same has been implemented in ANSYS customization toolkit (ACT) in Python.

Convective heat transfer coefficients (HTCs) are specified on the outer surfaces of the metal regions exposed to seawater as shown in Fig. 7. The HTCs specified on the outer surface of the metal bodies are quite critical and affect the results to a great extent. The major limitation in using thermal FEA is the specification of heat transfer coefficients from standard empirical correlations from existing

B: Steady-State Thermal 8/29/2016 11:35 AM Heat Flow: $0 . \mathrm{W}$

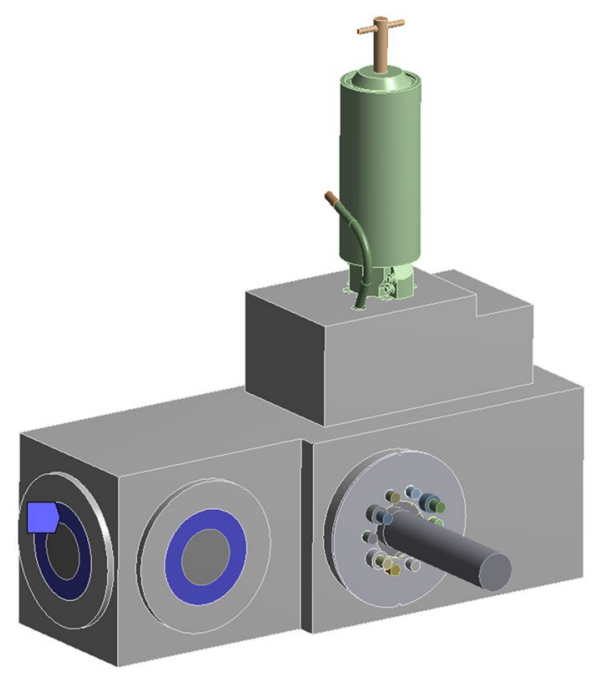

Fig. 8 Adiabatic boundary condition

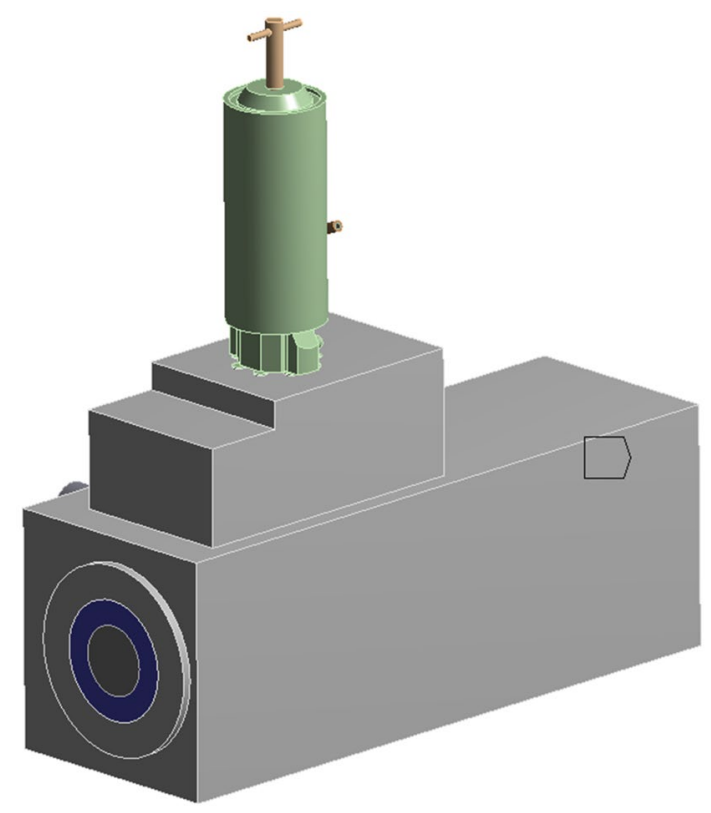

Fig. 9 Adiabatic boundary condition

literature. In a CFD based approach, the heat transfer coefficients evolve as part of the solution and are considered as more accurate. In the present study, the heat transfer correlations used are from existing literature and have been properly validated and tested in a number of thermal analysis cases.

Adiabatic boundary condition has been specified as shown in Figs. 8 and 9. These are the connecting surfaces to the mating parts.

\section{Optimization problem specification}

\section{Single objective function}

The insulation optimization problem happens to be a single objective function problem, as the main objective is to minimize the insulation volume/weight on the gate valve body.

Objective function $=$ Minimize (insulation volume); insulation volume $>0 \mathrm{~m}^{3}$.

\section{Constraints}

The constraint for this problem is the minimum temperature of the bore must be greater than the hydrate formation temperature (HFT assumed to be $21^{\circ} \mathrm{C}\left[\sim 70^{\circ} \mathrm{F}\right]$ ).

\section{Variables}

The design/independent variables are the parameterized dimensions of the insulation on the gate valve body. 
Fifteen geometric dimensions have been considered for the present investigation. It is always advisable to keep fewer parameters as possible, as the computational time increases with the number of parameters.

\section{Results and discussion}

The thermal FEA analysis for the present study is performed in two steps:

1. Perform a steady state thermal FEA to determine the temperature distribution in the gate valve.

2. The solution of the steady state thermal FEA is used for performing the transient FEA analysis. The results from the steady state analysis serve as the initial condition for the transient analysis. The temperature on the production bore is released, as it is the prime area of focus in a cooldown analysis. This type of analysis requires a finer

Fig. 10 Geometry before optimization - insulation volume $=0.14 \mathrm{~m}^{3}$ time step as a larger time step would lead to a loss of flow information.

\section{Steady state results}

The contours of steady state temperatures before and after optimization, extracted at the mid plane are presented in Figs. 10 and 11. As it can be seen from figures, the temperature of the components closer to the production/flow bore are relatively hotter and are pretty close to the production fluid temperature. The temperature gradient can be seen through the insulation layer as it resists conduction. The thermal diffusivity of the insulation material plays a crucial role in retaining the temperature within the thermal envelope/ computational domain. In Fig. 10, (i.e., geometry before optimization) the temperature does not percolate through the insulation layer on the areas closer to the actuator of the gate valve. The portion of the insulation closer to the actuator can be safely removed without compromising on the thermal performance of the system. It may seem that the

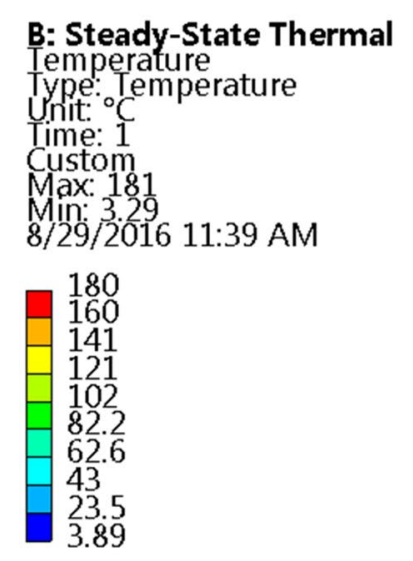




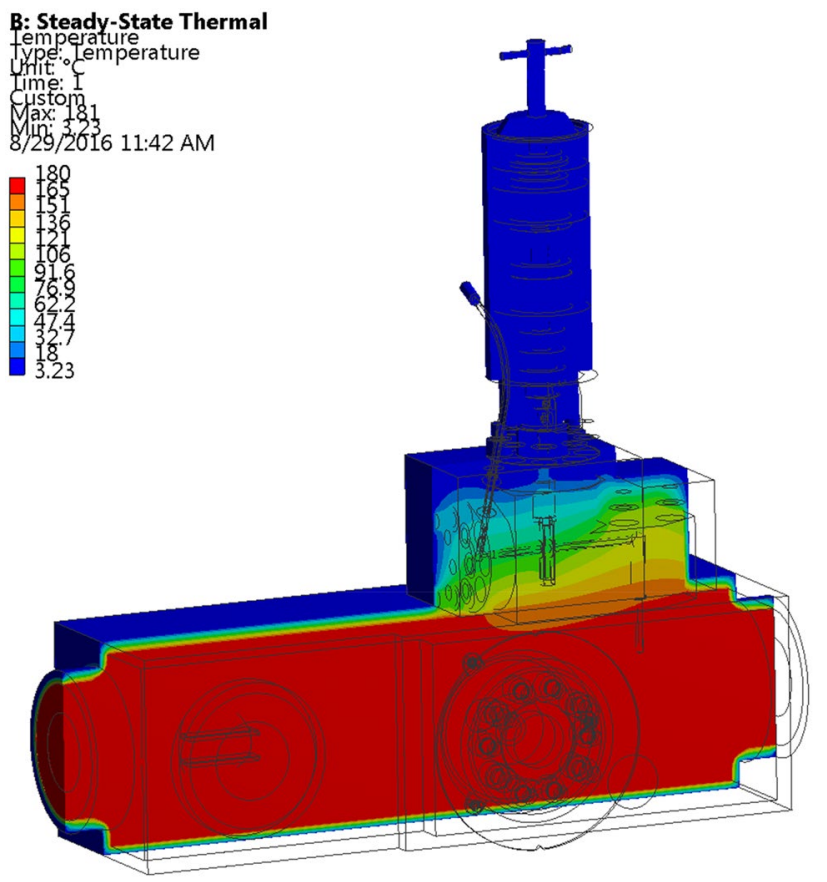

Fig. 11 Geometry after optimization - insulation volume $=0.0466 \mathrm{~m}^{3}$

removal of a small portion of the insulation may not justify the additional computational effort, but as a whole this could add up to a significant cost savings as there are several such valves in a subsea production system. It can be seen from Figs. 10 and 11 that the actuator is always cold, and it serves as a heat sink. The actuator cannot be insulated and must be accounted for in the thermal analysis. If a portion of the actuator closer to the valve can be insulated, it could prevent the formation of a cold spot and subsequently prevent hydrate formation during prolonged shut-in of the wells. The volume of the insulation in Fig. 10 is $0.14 \mathrm{~m}^{3}$ and in Fig. 11 is $0.0466 \mathrm{~m}^{3}$. This is a substantial saving of insulation.

\section{Results: transient analysis}

The results obtained from the steady state analysis are supplied as initial conditions to the transient/cooldown analysis. The production fluid temperature is released, and it can cooldown during the transient analysis. The temperature in the production bore is the main area of concern and hence the temperature of the production fluid after $10 \mathrm{~h}$ is extracted both before and after optimization. The temperature contours in the outer surface of the production fluid is shown in Figs. 12 and 13. As it can be seen from figures, the minimum temperature in both the cases is well above $21^{\circ} \mathrm{C}$.

The lack of experimental data on this critical topic of interest hampers one's ability to validate the optimization models used for the present study. The optimization

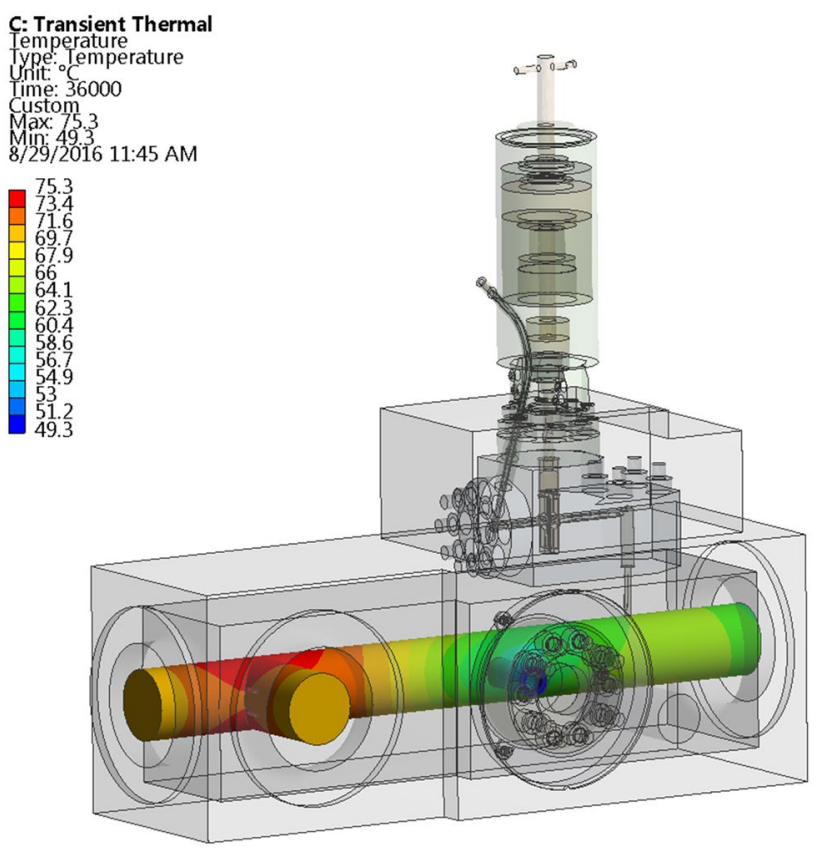

Fig. 12 Geometry before optimization - insulation volume $=0.14 \mathrm{~m}^{3}$

techniques that are used for the present investigation are already well tested and proven for several mathematical functions and applications those are not necessarily restricted to subsea engineering. The project/product engineers involved in subsea projects design the insulation system with a crude rule of thumb and do not pay adequate attention to optimization. The proposed methodology presents a better way to

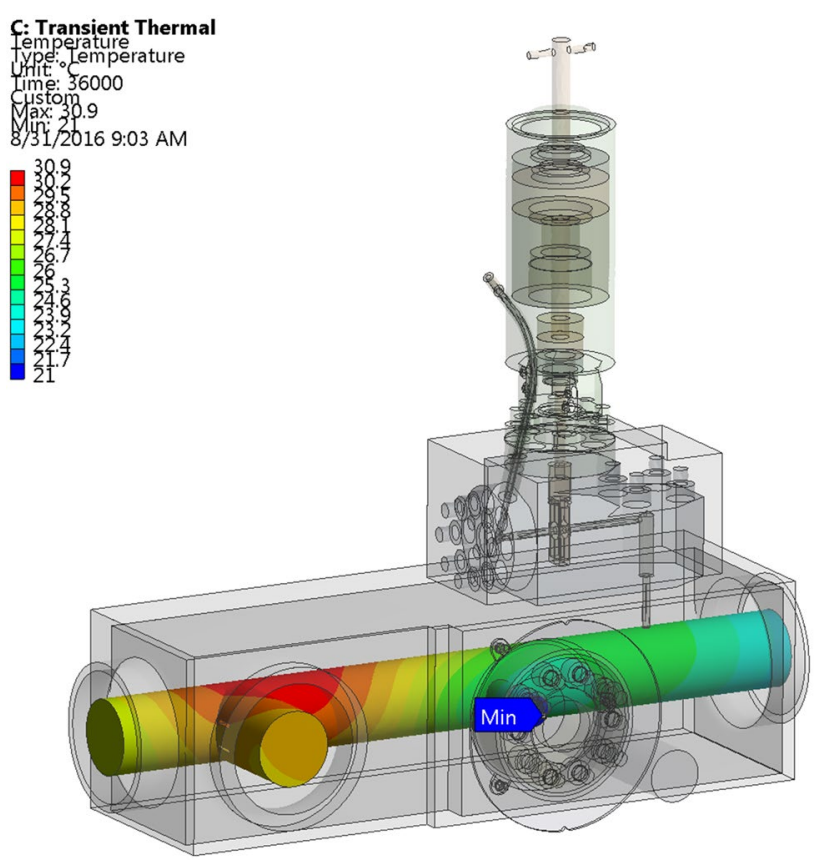

Fig. 13 Geometry after optimization - insulation volume $=0.0466 \mathrm{~m}^{3}$

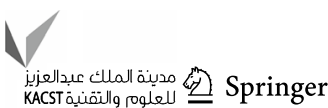




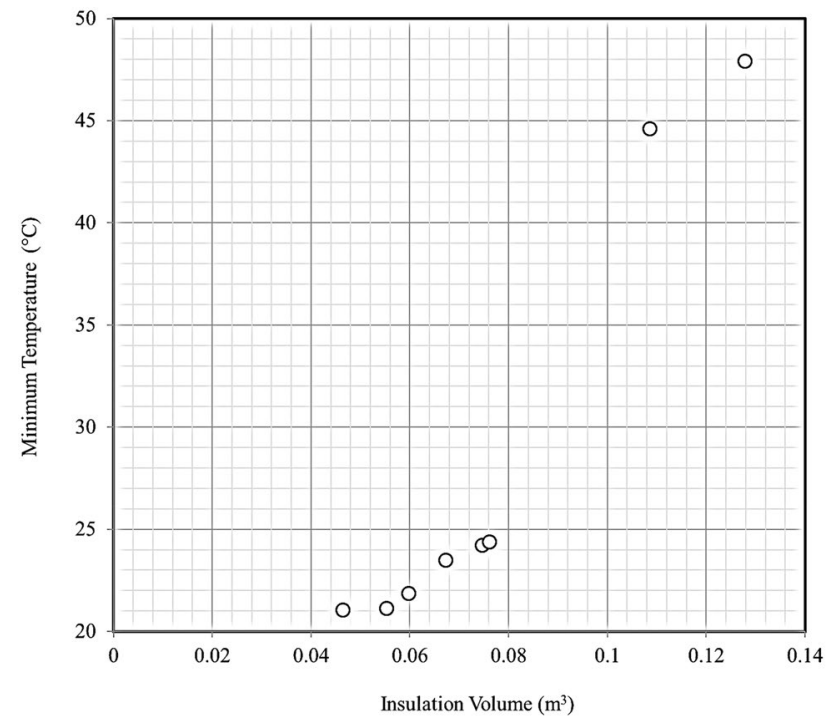

Fig. 14 Minimum temperature $\left({ }^{\circ} \mathrm{C}\right)$ corresponding to various insulation volume-nonlinear programming with quadratic Lagrangian (NLPQL) method

design insulation on subsea systems without compromising on the integrity of the system.

Trade-off chart for the optimization study performed using the nonlinear programming with quadratic Lagrangian (NLPQL) method is shown in Fig. 14.

The insulation volume required to maintain a minimum temperature of $21^{\circ} \mathrm{C}$ using the NLPQL method is $0.0466 \mathrm{~m}^{3}$. To compare/cross-check the results obtained using the Nonlinear Programming with Quadratic Lagrangian (NLPQL) method the same test case is run using the adaptive singleobjective optimization (ASO) method. The results obtained using both the methods are almost the same, but the computation time is less in the case of the NLPQL method as it uses a different approach for creating the initial sample.

The initial sample in the case of the ASO method is created using the Optimal Space Filling (OSF) design of experiments. The ASO is a hybrid optimization method using Optimal Space Filling (OSF), a Kriging response surface, Mixed-Integer Sequential Quadratic Programming (MISQP), and domain reduction in a direct optimization system.

An initial sample size of 200 data points has been considered for the present investigation using the ASO method. A coarser time step has been considered for the optimization analysis and the results are once again verified with a finer time step. A pareto set of minimum temperature corresponding to various insulation volume using the ASO method is presented in Fig. 15.

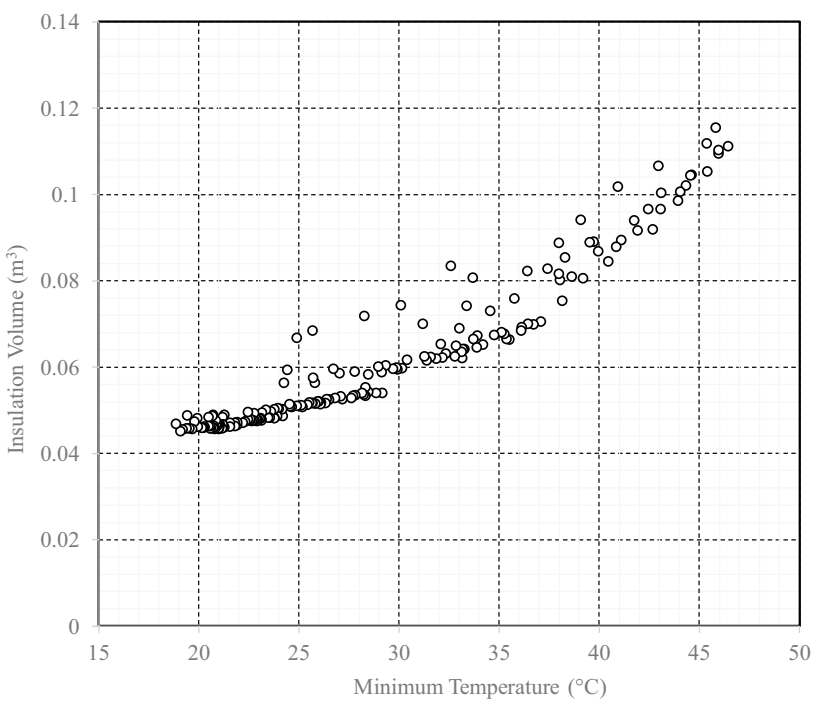

Fig. 15 Pareto set of minimum temperature $\left({ }^{\circ} \mathrm{C}\right)$ corresponding to various insulation volume-adaptive single objective (ASO) method

\section{Comparison between the NLPQL and ASO methods}

A comparison between the results obtained from the NLPQL and ASO methods is shown in Table 3.

The results obtained using both the methods are almost the same, but the computation time is less in the case of the NLPQL method, as it uses a different approach for creating the initial sample and moreover it is a local search for optima. However, the ASO method delivered many more design points ( 211 vs 8 ) than did the NLPQL method, as evident when comparing Figs. 12 and 13. Note that computation time for either method depends on the number of selected iterations as well.

The results obtained using both the methods are almost the same but the computation time is less in the case of the NLPQL method, as it uses a different approach for creating the initial sample and moreover it is a local search for optima.

\section{Conclusion}

In the present work, the optimization of insulation on a subsea gate valve has been numerically analyzed using a judicious combination of Design of Experiments (DOE) and Optimization algorithms. The optimization study has been carried out using NonLinear Programming with Quadratic Lagrangian (NLPQL) and Adaptive Single Objective (ASO) optimization methods. It is seen that both the methods yield the same results for the single objective constrained optimization problem under investigation. 
Table 3 Comparison between the NLPQL and ASO methods

\begin{tabular}{|c|c|c|c|c|}
\hline Optimization method & $\begin{array}{l}\text { Minimum tempera- } \\
\text { ture }\left({ }^{\circ} \mathrm{C}\right)\end{array}$ & $\begin{array}{l}\text { Original insulation } \\
\text { volume }\left(\mathrm{m}^{3}\right)\end{array}$ & $\begin{array}{l}\text { Optimized insulation } \\
\text { volume }\left(\mathrm{m}^{3}\right)\end{array}$ & $\begin{array}{l}\% \text { Reduction } \\
\text { in insulation } \\
\text { volume }\end{array}$ \\
\hline $\begin{array}{l}\text { Nonlinear programming with quadratic Lagrangian } \\
\text { (NLPQL) }\end{array}$ & 21.02 & 0.14 & 0.0466 & 66.8 \\
\hline Adaptive single objective optimization (ASO) & 21.02 & 0.14 & 0.0461 & 67.1 \\
\hline
\end{tabular}

The results obtained from the analysis are quite promising and it is evident that the proposed methodology can lead to substantial savings in cost and weight of the subsea structures. The optimization exercise on the insulation of a gate valve body reveals the following: To maintain an internal/ bore temperature greater than $21^{\circ} \mathrm{C}\left(\sim 70{ }^{\circ} \mathrm{F}\right)$ an insulation volume of $0.0466 \mathrm{~m}^{3}$ itself is sufficient. The present/ original design has an insulation volume of $0.14 \mathrm{~m}^{3}$. The optimized design leads to a reduction of more than $66.7 \%$ on the insulation volume. If the objective of the insulation was to maintain a minimum internal/bore temperature of $40^{\circ} \mathrm{C}$ for a duration of $10 \mathrm{~h}$, then an insulation volume of less than $0.1 \mathrm{~m}^{3}$ itself would suffice the requirement. This is equivalent to a reduction of $30 \%$ on the insulation volume. The proposed methodology can also be extended to a CFD based approach for complex subsea geometries such as Christmas Trees (XT) and manifolds. The proposed technique could serve as an effective substitute for the crude approaches used by equipment suppliers of subsea projects.

Funding The authors received no specific funding for this work.

\section{Compliance with ethical standards}

Conflict of interest The authors declare that they have no conflict of interest.

Open Access This article is licensed under a Creative Commons Attribution 4.0 International License, which permits use, sharing, adaptation, distribution and reproduction in any medium or format, as long as you give appropriate credit to the original author(s) and the source, provide a link to the Creative Commons licence, and indicate if changes were made. The images or other third party material in this article are included in the article's Creative Commons licence, unless indicated otherwise in a credit line to the material. If material is not included in the article's Creative Commons licence and your intended use is not permitted by statutory regulation or exceeds the permitted use, you will need to obtain permission directly from the copyright holder. To view a copy of this licence, visit http://creativecommons.org/licenses/by/4.0/.

\section{References}

Bieker HP, Slupphaug O, Johansen TA (2006) Real time production optimization of offshore oil and gas production systems: a technology survey. In: SPE intelligent energy conference and exhibition held in Amsterdam, The Netherlands, 11-13 April. SPE 99446

Bieker HP, Slupphaug O, Johansen TA (2007) Well management under uncertain gas/ or water/oil ratios. In: Proceedings of digital energy conference and exhibition, society of petroleum engineers, Houston, TX, USA

Bhattacharyya SK, Cheliyan AS (2019) Optimization of a subsea production system for cost and reliability using its fault tree model. Reliab Eng Syst Saf 185:213-219. https://doi.org/10.1016/j. ress.2018.12.030

Cengel YA, Ghajar AJ (2010) Heat and mass transfer, 4th edn. McGraw Hill, New York

Cheng H, Yuxi W, Jiankun Y, Segen FE, Marcelo IL (2020) Optimization of pipe insulation volume for a subsea production system. J. Offshore Mech. Arct. Eng. 142(4):041801. https://doi. org/10.1115/1.4046001 (OMAE-18-1103)

Durrer EJ, Slater GE (1977) Optimization of petroleum and natural gas production-a survey. Manag Sci 24(1):35-43. https://www. jstor.org/stable/2630726.

Elgoeter SM, Slupphaug O, Johansen TA (2010) A structured approach to optimizing offshore oil and gas production with uncertain models. Comput Chem Eng 34(2):163-176

Incropera FP, Dewitt DP, Bergman TL, Lavine AS (2006) Fundamentals of heat and mass transfer, 6th edn. Wiley, New York

Jahanshahi E, Grimstad B, Foss B (2016) Spline fluid models for optimization. IFAC-PapersOnLine 49(7):400-405

Mochizuki S, et al (2004) Real time optimization: classification and assessment. In: SPE annual technical conference and exhibition, Houston, TX, USA. SPE 90213

Pavel B, Halvard K, Jaroslav S (2014) Automated insulation optimization for subsea equipment. In: The 24th international ocean and polar engineering conference, 15-20 June, Busan, Korea. ISOPE-I-14-258

Philip S, Murilo FR, Juliana SB, Djalene MR, Breno PJ (2020) Optimization of subsea production systems layout considering flowline diameters. In: The 30th international ocean and polar engineering conference, 11-16 October. ISOPE-I-20-2147

Pribytkov EA, Zolotukhin AB, Gudmestad OT (2014) Optimization of integrated template structures for arctic subsea-production systems. Oil and Gas Facilities Journal. 3(4):47-53. https://doi. org/10.2118/166879-PA (SPE-166879-PA)

Ramdial, A.M., Hudson, N.H., Pike, R., Rodrigeuz, G.C., Stratman, M.S., and Sama, S.S. 2009. Model-based optimisation of a gas production system - the bp trinidad field optimiser. In: SPE annual technical conference and exhibition held in New Orleans, LA, USA, 4-7 October 2009. SPE 124720-PP

Saputelli LA, et al (2003a) Promoting real-time optimization of hydrocarbon producing systems. Offshore In: Europe 2003, Aberdeen, UK. SPE 83978

Saputelli L, Nikolaou M, Economides MJ (2003b) Self-learning reservoir management. In: SPE annual technical conference and exhibition, Denver, Colorado, USA. SPE 84064 
Yang J, Lourenco MI, Estefen SF (2018) Thermal insulation of subsea pipelines for different materials. Int J Press Vessels Pip 168:100109. https://doi.org/10.1016/j.ijpvp.2018.09.009

Zhang H, Liang Y, Ma J, Shen Y, Yan X, Yuan M (2017) An improved PSO method for optimal design of subsea oil pipelines. Ocean Eng 141:154-163. https://doi.org/10.1016/j.oceaneng.2017.06.023
Publisher's Note Springer Nature remains neutral with regard to jurisdictional claims in published maps and institutional affiliations. 